\title{
Organizational Change: Where Have All the Leaders Gone When Creating Anti-Harassment Cultures
}

\section{Dr. Krystal Brue, Ph.D. Cameron University}

\begin{abstract}
Media coverage of recent high-profile sexual harassment scandals and subsequent \#MeToo publicity confirms that sexual harassment continues to plague corporate cultures. Organizations have previously relied on professional training and policy creations to address workplace misconduct. These initiatives are primarily predicated on legal and compliance efforts to reduce misconduct and maintain more harassment free environments. Even with calls from regulatory agencies and media coverage, corporate cultures do not appear to have changed. This exploratory investigation suggests that organizations continue to rely on established methods of addressing sexual harassment and should utilize behavioral modeling to improve corporate cultures. Ideas forwarded within this paper will begin discussions regarding the use of behavioral modeling by leaders to solidify improved anti-harassment cultures.
\end{abstract}

Keywords: Sexual Harassment, \#MeToo, Behavioral Modeling, Culture Change, Organizational Change

Classification: Practice and Research

Methodologies: Mixed and Theoretical Framework

Category: Human Resources and Leadership

\section{Introduction}

earning and adapting to change are critical elements of organizational sustainability. The learning process allows employees to capture knowledge, process information through experiential lessons, and implement new responses in order to solve problems and improve the organization (De Luca \& Rubio, 2019; García-Morales et al., 2012; Xie, 2019); learning is facilitated by management stimulation and requires cognitive and behavioral changes in order to incorporate, institutionalize, and imbed new behaviors within organizational systems and routines (Berson et al., 2015). Often employee learning and organizational change is accomplished using behavioral role models (Annosi et al., 2018; García-Morales et al., 2012). Leadership modeling has proven to be a meaningful component resulting in the successful adaptation and sustainment of organizational change (Berson et al., 2015; Stan \& Puranam, 2017).

Modeling, which is operationalized through directing, coaching, and exhibiting behavioral norms and expectations, unlocks an organization's previous and no longer appropriate patterns of behavior in order to adapt and solidify new patterns of performance (Stan \& Puranam, 2017; Yaffe \& Kark, 2011). According to Schein (2004) and Dragoni (2005), behavioral modeling is the primary means for leaders to 
transmit belief systems into action and functions as a core process by which organizations develop, change, and sustain new organizational cultures.

The connection among role modeling, behavioral modification, and cultural change within organizations is currently relevant, as leadership appeals have intensified in the wake of corporate scandals of misconduct, including recent high-profile harassment situations (Boje et al., 2004; Knottnerus et al., 2006; Owens \& Hekman, 2012). Many high-profile harassment cases have attributed a sense of entitlement, self-importance, and unrestricted prerogatives to allow perpetrators to act above the law with egregious misconduct (Boje et al., 2004; Knottnerus et al., 2006; Owens \& Hekman, 2012). Additional case examinations have ascribed internal and external causes such as the harasser's overconfidence, narcissism, lack of ethical base, and inadequate organizational commitment as some of the primary reasons why misconduct continues (Chatterjee \& Hambrick, 2007; Dotlich \& Cairo, 2003). Recent coverage of workplace harassment problems provides organizational leaders an opportunity to examine the effectiveness of current workplace strategies used to address and minimize sexual misconduct.

Employers increasingly use training as a vehicle to develop, inform, and educate employees (Ho, 2016; Lacerenza et al., 2017), and the primary strategy for addressing sexual misconduct has been the implementation of workplace policies and employee training programs (Quick \& McFadyen, 2017). However, scholars acknowledge a lack of research investigating if organizational policies and training effectively reduce misconduct and create anti-harassment cultures (Cheung et al, 2018; Dobbin et al., 2011; Hennekam \& Bennett, 2017; Roehling \& Huang, 2018). The purpose of this exploratory article is to (a) examine leadership modeling research and its impact on organizational change initiatives, (b) review findings from an exploratory research project which examined how businesses were implementing antiharassment initiatives considering recent news and social media coverage of high-profile sexual harassment cases, and (c) apply leadership modeling and organizational change research within the framework of creating anti-harassment cultures. This analysis does not imply that organizational leaders have not created anti-harassment cultures, but rather considers the extent to which businesses have adopted recommended strategies to minimize workplace misconduct; additionally, this inquiry calls for increase behavioral modeling from leadership in order to create, develop, and preserve anti-harassment cultures.

This topic is relevant to management and leadership educators and human resource practitioners for reviewing workplace routines and policies as well as for developing emerging organizational leaders. This article contributes to the existing body of knowledge by examining current contexts for workplace sexual harassment, applying a new meta-framework for addressing workplace anti-harassment initiatives, and offering leadership education recommendations for addressing this timely and relevant topic.

\section{Modeling as Integrators for Cultural Change}

Leaders, acting as conduits of change, help to define and shape organizations (Zhang et al., 2019). Leadership and organizational culture researchers (Denison \& Mishra, 1995; Sarros et al., 2008; Zhang et al., 2019) view leaders as architects of cultural change, by the roles that they play and through their substantive, visible, and behavioral modeling. Modeling, an exercise in social influence, facilitates change through an integrative process by allowing noted figures to operate as information channels and engage their followers' personal value systems (Battilana \& Casciaro, 2013; Sarros et al., 2008; Stan \& Puranam, 2017). Response expectations are demonstrated by observing a desired model and often then reproduced by the observer (Manz \& Sims, 1981); a simple example of this is when a new employee observes a ranking individual's behavior, such as meeting behaviors or interactions with subordinates or clients, the new employee frequently imitates the behavior. Viewed through a more systemic lens, when models act as 
integrators, they facilitate and coordinate adaptation by reinforcing information shared about organizational standards or changes.

Modeling has been used as a training technique in businesses for over 50 years. In the early 1970s, General Electric and AT\&T were among the first organizations who used behavioral modeling as a training technique to foster positive supervisor-employee communication and interactions, including modeling how to give recognition, address disciplinary issues, introduce an organizational policy change, and improve inadequate performance (Burnaska, 1976; Moses \& Ritchie, 1976). Use of modeling was found to be a powerful tool in learning and developing skills; proponents acknowledge that modeling plays a vital role in long-term behavior sustainment, but caution that implementation of modeling can be carelessly or inadequately implemented resulting in ineffective internalization and unproductive change management (Manz \& Sims, 1983; Moses \& Ritchie, 1976).

Despite these initial cautions, application of modeling as an integrator for cultural change remains applicable. Creating a culture of employee appreciation, supporting work-life balance, and fostering creativity and innovation are a few examples of cultural shifts where modeling by leadership would solidify and propagate preferred behaviors (Ellinas et al., 2017). Additionally, by legitimizing conduct for others to see, modeling has proven to facilitate the rate of adoption by leveraging expertise, prestige, and power status to improve the coordination of change (Stan \& Puranam, 2017). Using their social influence, organizational leaders who model change behaviors help to neutralize change opponents, minimize inadequate change adoption, promote learning, foster preferred behaviors, and facilitate change sustainment (Battilana \& Casciaro, 2013; Owens \& Hekman, 2012).

Effective modeling means that leaders must demonstrate a willingness to learn and eagerly and publicly represent the desired behavior (Owen \& Hekman, 2012). Because senior leadership are in positions to influence organizational change by shifting culture and creating new identities (Sarros et al., 2008), they are strategically placed to model behaviors and subsequently contribute to a new organizational framework. Organizations which fail to keep pace with the changing internal and external environment often do so because of their rigidity; however, Owen and Hekman (2012) suggest that modeling may crack the rigidity which is often associated with change resistance. By using social influence and connections, modeling can influence employees who are ambivalent, inconsistent, and conflicted, transforming apathy to willingness (Battilana \& Casciaro, 2013; Cinite \& Duxbury, 2018). Behavior modeling allows leaders to demonstrate vicarious learning and behavior patterning to influence employee decision making, promote pro-social behaviors, and minimize counterproductive actions (Brown \& Treviño, 2006; Freiwald et al., 2015).

Sims and Brinkman (2002) conclude that leaders create and perpetuate appropriate behavioral norms and processes within their organizations, form their ethical organizational culture, and construct their organization's commitment to a certain corporate climate. Similar to Zhang's et al. (2019) conclusion that ethical modeling by leaders begat employees who were more willing to reciprocate favorable organizational citizenship behaviors, Owen and Hekman's (2012) proposition of humility modeling, and Manz and Sim's (1981) assertion that modeling drives organizational change, this investigation considers if the simple, yet essential act of behavioral modeling could help to endorse and elevate appropriate conduct in the minds of employees, triggering the perception that anti-harassment behaviors are not merely a legal compliance or a "have to be politically correct" issue, but are considered more of an intrinsically valued behavior within the organization and its employees.

\section{Organizational Learning through Modeling}

Leadership theorists have viewed organizational change using relational and discursive activities within a social learning model (Bandura, 1989; Jacobs \& Coghlan, 2005). Bandura (1989) suggested that 
individuals learn from personal interaction or by observing modeled behavior and leaders influence followers by transmitting values, attitudes, beliefs, and behaviors through their conduct. Thus, employees look to role models for behavioral cues and direction (Moore et al., 2019). Other change theorists (Brown et al., 2005; Waldman et al., 2001) note how employees learn what to do, and conversely what not to do by observing role models; these theorists also refer to the significant impact of role modeling to expedite social learning and facilitate change.

Social learning through role modeling allows organizational leaders to establish stronger dyadic interactions with employees, influencing their behaviors. Bottomley et al. (2014) viewed leadership modeling as an integration and learning function, using their leadership style and role to positively develop the organization's human capital. However, despite evidence supporting leadership modeling, organizations frequently utilize employee training or the enactment of clarified policies and procedures as their primary means of addressing issues or attempting to change deviant behaviors (Litzky et al., 2006). Treviño and Brown (2005) advocate:

Leaders are coming under increasing scrutiny not only because many senior executives are accused of having committed unethical acts but also because of the role that leaders at all levels are thought to play in managing the ethical (and unethical) conduct of organizational members. (p. 69)

Based on ethical development research, employees typically reason and act at a conventional level of cognitive moral development (Treviño \& Brown, 2005). At a conventional-level, employees consider rules and laws as well as the expectations of significant others, such as organizational leaders and supervisors, when determining the ethically right thing to do (Moore et al., 2019; Treviño \& Brown, 2005). This means that managers and supervisors not only serve as vital role models in conveying and demonstrating moral guidance for employees but also provide vital cues as to appropriate and inappropriate behaviors within their organization.

Applying social learning and social exchange theories, Moore et al. (2019) concluded that when leaders model ethical behavior, employees are less likely to engage in deviant behaviors, more inclined to activate their self-regulatory process, and mitigate misconduct throughout an organization. Hinyard and Kreuter (2007) extend social learning and exchange theories by suggesting that leadership role modeling and leadership narrative endeavors create attitude accessibility, which in turn drives and predicts follower behaviors, reduces counterarguing, and advances desired social norms. Clearly behavioral modeling influences followers' behaviors; however, modeling has not been recognized as an overt or proactive approach applied to creating anti-harassment cultures within the workplace.

\section{Multidimensional Reactions to Cultural Change}

Over the past several decades, academic researchers and business press have considered the constructs related to dimensional reactions to change (Cinite \& Duxbury, 2018; Piderit, 2000). A plethora of individual motives exists for opposing or reacting negatively to change; failing to acknowledge urgency, counterproductive behaviors, status quo maintenance, fear of the unknown, routine preference, past change complications, and change resistant personalities have been noted as perceived negative reactions to change (Chung et al., 2012; Cinite \& Duxbury, 2018; Zimmerman, 2006).

Herscovitch and Meyer (2002) conceptualized change and change resistance through an organizational commitment framework. Their research noted reactions to change and indicated enactment and sustainment of change was influenced by (a) affective commitment, the desire to support change; (b) normative commitment, the sense of obligation to support change; and (c) continuance commitment, the fear of costs resulting from failure to support change. Battilana and Casciaro (2013) 
extended this research by categorizing change opponents as either change resistors who possess a firmly established negative attitude toward change initiatives or 'fence-setters' who are ambivalent regarding change proposals. Resistance to change may range from passive resistance to open hostility (Kellogg, 2011). Chung et al. (2012) and Piderit (2000) also classified change resistors and examined resistance reactions through three dimensions, including emotional (affective), cognitive, and intentional (behavioral) resistance. In Chung's et al. (2012) framework, affective resistance to change encompasses an employee's feelings of anger or anxiety toward adjustment, cognitive resistance involves the negative doubts, concerns, and thoughts regarding the need or engagement of change, and behavioral resistance refers to responses, including actions or intent to act, which demonstrate opposition and disapproval. Research considering the perceptional affective, cognitive, and behavioral resistance to change has revealed a causal chain dynamic; thus, affective and cognitive resistance to change results in behavioral resistance (Chung et al., 2012; Piderit, 2000).

Similarly, important considerations to change sustainment include the bidirectional connection between attitudes and behaviors (Kroesen et al., 2017) as well as the impact of relationship characteristics on change outcomes (Ashnai et al., 2016). Perceptions and attitudes have been shown to affect a wide range of organizational behaviors, including discrimination and harassment; conversely, changing behaviors also results in attitude modifications for employees (Holland et al., 2002; Kroesen et al., 2017). While researchers have identified several moderating factors, such as attitude strength, social pressures, and relationship linkage between feelings and actions, which impact the attitude behavior connection (Ajzen \& Fishbein, 1977; Holland et al., 2002; Siegel et al., 2014), behavioral and attitudinal changes do not occur in isolation. Ashnai et al. (2016) concluded that organizations who wish to enhance performance and successfully adapt to changing environments must fully manage business relationships among employees, management, and leadership.

\section{Sexual Harassment in Today's Workplace}

Harassment includes any form of discrimination which violates employment laws including Title VII of the 1964 Civil Rights Act, 1991 amendment to the Civil Rights Act, 1967 Age Discrimination in Employment Act, and 1990 Americans with Disabilities Act (Becton et al., 2017). While the Civil Rights Act was passed in 1964, it was not until subsequent legal interpretations and the formation of the Equal Employment Opportunity Commission (EEOC) in 1980 that sexual harassment was considered discrimination. Despite accepted legal and legislative designations as well as years of educational focus and media attention, including recent media coverage, a single, comprehensive, and broadly accepted definition of sexual harassment has not been established (L. Jackson, 2018; Quick \& McFadyen, 2017).

Functionally, harassment involves offensive conduct or improper behavior considered severe or pervasive in which a reasonable person would consider the words or behavior to be intimidating, hostile, or abusive (EEOC, 2018). While legal definitions of sexual harassment have been narrowly defined based on situational criteria, diverse themes have emerged when examining operational definitions of this phenomena (Soucek \& Schultz, 2019). Related constructs and evolving classifications including power differential, location of the workplace misconduct, perceptions versus intent, victim's sex, microinequalities or microaggressions, and related topics such as gender harassment and bullying have been viewed and defined differently depending upon unique situations and contexts (O'Donohue et al., 1998; Tonowski, 2018). Workplace sexual harassment definitions continue to evolve and encompass same sex harassment, egregious demands for sex, sexual advances, unwanted sexual encounters, sex talk, requests for sexual favors, offensive or sexual jokes, and stereotypical or demeaning comments (Gertner, 2018; Quick \& McFadyen, 2017), adding to both the ambiguity and evolution of this issue. 
The EEOC and legal findings have helped to establish organizational liability guidelines and accepted parameters for determining sexual harassment in the workplace (Back \& Freeman, 2018; Sherwyn et al., 2001; Soni \& Soni, 2018). Harassment is typically classified by two behaviors including (a) quid pro quo, a retaliatory consequence for accepting or refusing sexual advancement, and (b) workplace conduct (verbal or physical) that is severe or pervasive creating an environment that a reasonable person would consider hostile, abusive, or intimidating (Harris v. Forklift Systems, Inc., 1993; Meritor Saving Bank v. Vinson, 1986). Additional findings from Barnes v. Costle (1977) and Meritor Saving Bank v. Vinson (1986) solidified that employers should be held liable for wrongdoings that remain within the scope of employment and could be held negligent for not exercising reasonable care to protect and educate their employees. Subsequent legal cases including Burlington Industries v. Ellerth (1998) and Farager v. Boca Raton (1998), allowed employers to provide an affirmative defense arguing less liability if they had established anti-harassment policies and reporting procedures, despite whether victims utilized the procedures. Ellerth and Farager cases stimulated businesses to adopt sexual harassment policies and reporting procedures to mitigate harassment occurrences. Even with these legal cases, continued legal findings, and EEOC focus, the vagueness of phrases including "hostile environment" and "reasonable person" complicates individual and organizational awareness of this matter and often obscures how companies address and react to sexual misconduct (Roehling \& Huang, 2018).

More recently, high-profile sexual harassment scandals and \#MeToo publicity confirms that sexual harassment continues to pose issues for today's businesses. Cases such as Harvey Weinstein, Ben Affleck, Ken Friedman, and Matt Lauer confirm that harassment remains prevalent today (Crabb, 2018; Hemel \& Lund, 2018; Traub \& Van Hoose Garofalo, 2019). Many of these recent highly publicized cases involve a single individual purposefully and egregiously harassing multiple subordinate victims, over 85 in Weinstein's case (R.A Jackson, 2018).

\#MeToo initially began in 2006 when Tarana Burke called for victims of sexual harassment and assault to make themselves known by voicing the pervasive extent of this problem (Fortado, 2018; Shugerman, 2017). \#MeToo gained extensive media attention in 2017, when actress Alyssa Milano asked victims of sexual harassment to acknowledge the extent of misconduct in the U.S. by posting \#MeToo; within 24 hours, over 12 million Facebook posts and over 500,000 tweets were made creating a national conversation regarding sexual harassment (Fortado, 2018; Greene, 2018; Prasad, 2018; Xiong et al., 2018).

Despite organizational strategies to minimize misconduct, harassment continues to be an issue for organizations and more research regarding effective strategies for reducing harassment and creating improved anti-harassment cultures is needed (Quick \& McFadyen, 2017). Data from the EEOC confirms that sexual harassment continues to plague businesses today. The EEOC reported from 2010 through 2016, approximately 12,000 cases of sexual misconduct were reported annually (Haller, 2018). Additionally, in 2015 nearly one-third of the 90,000 charges received by the EEOC involved allegations of harassment in the workplace (EEOC, 2018). Data from sexual harassment victims reveal that employees experience an array of negative outcomes including reduced job satisfaction, work productivity issues, withdrawal, increased anxiety, perceived injustice, neglect, and cognitive difficulties (Benavides-Espinoza \& Cunningham, 2010; Quick \& McFadyen, 2017). With the pervasiveness of the issue and considering the extensive negative outcomes related to harassment, examining this issue further is necessary and appropriate.

Current organizations have relied primarily on organizational training initiatives and workplace policies to create anti-harassment cultures (Johnson, 2018; Quick \& McFadyen, 2017). However, Victoria Lipnic, EEOC Commissioner concluded that 30 years of research revealed that current workplace harassment training programs had not resulted in meaningfully reducing workplace harassment occurrences (Folz, 2016). In October 2017, the EEOC launched a new initiative called Respectful 
Workplaces, aimed at creating and promoting more civil and harassment free workplaces (EEOC, 2018). The EEOC wanted to expand its traditional anti-harassment recommendations, which focused on legal definitions and liability standards and had inadequately reduced levels of workplace harassment, and move towards creating civil, courteous, and bully-free workplace conduct (EEOC, 2018). Acknowledging cognitive and behavioral resistance to change and data confirming limited progress creating antiharassment workplace cultures, the purpose of this inquiry was to examine if organizational leadership were effectively addressing affect, cognitive, and behavioral dynamics in the effort to reduce sexual harassment.

\section{Research Questions}

The initial intent of this exploratory research project was to examine what initiatives organizations have implemented to create anti-harassment cultures. With the onset of the \#MeToo movement and the EEOC's call for improved workplace respect initiatives, I sought to examine what EEOC recommended practices were used to minimize misconduct and promote positive workplace behaviors. While the \#MeToo movement and the EEOC's recommendations are new phenomenon, training and organizational policies have been implemented for several years, with little or conflicting outcomes on reducing misconduct in the workplace. Examining this subject from a behavioral modeling perspective sheds new light on a long-term organizational and societal issue.

\section{Research Methods and Design}

This research project was part of a larger undertaking aimed at investigating sexual harassment from a legal, compliance, and human resource (HR) management perspective. Research components for this project utilized a subset of questions which addressed organizational and leadership efforts related to improving anti-harassment cultures within organizations. Prior to survey deployment, research approval was granted through the Oklahoma State Council of Human Resource Management (OKHR) and through the institution's Institutional Research Board process. All participants were members with OKHR State Council, which is a volunteer professional organization offering support and learning opportunities for HR professionals. Prior to taking the survey, respondents were informed of the study's purpose and content, research intent, and expectations of privacy.

\section{Survey Instrument}

A 54-question survey was created and based on the EEOC respectful workplace recommendations (EEOC, 2018). The questionnaire captured individual and organizational demographic questions including industry, organizational longevity, size, profit/non-profit status, as well as participant position level, longevity, and sex. The survey instrument also captured respondents' perceptions regarding their organizations' compliance policies and practices, training mechanisms, and organizational initiatives regarding sexual harassment prevention as well as the perceived impact of \#MeToo on current HR policies and practices. Questions regarding organizational compliance and anti-harassment initiatives were based on EEOC recommendations and focused on organizational funding, time allocation, communication strategies, and leadership commitment. Organizational policy questions, also based on EEOC recommendations, focused on ease of policy consideration, frequency of policy communication, and adherence to policy recommendations such as investigation practices, confidentiality, and retaliation. Training questions aimed to determine respondents' perceptions of types and audiences for antiharassment training, training curriculum, and training methodologies. Additional perception and observation questions were asked regarding workplace rituals and the impact of \#MeToo on antiharassment training, policies, and leadership practices.

\section{Procedures}


For five weeks in May through June 2018, the survey was available through the online survey platform, Qualtrics; the survey was emailed to 418 HR practitioners associated with OKHR. Ninety individuals opened and voluntarily participated in the survey. Eleven responses were deleted due to their incompleteness, leaving 79 respondents and a sample size of $19 \%$. Data was initially analyzed based on responses and then presented to the OKHR organization during two debriefing sessions. Debriefing sessions allowed practitioners to benefit from the results and begin to develop peer conversations regarding the subject. Debriefing sessions were approximately 90 minutes long, giving time for attendees to process and clarify results; a total of 83 attendees participated in the debriefing sessions.

\section{Results}

Results indicated that participants were employed primarily in energy (16\%), manufacturing (15\%), and financial (14\%) industries but also worked in other industries including aerospace (2\%), construction (5\%), defense (9\%), education (4\%), entertainment (4\%), food $(6 \%)$, health care $(10 \%)$, sales (9\%), utilities (4\%) and other (2\%) industries; $68 \%$ of businesses indicated that they were for profit. Organizations ranged in size from six to 70,000 employees, with an average employer size of 2,987, with $25 \%$ of the employers having less than 100 employees, $56 \%$ having less than 500 employees, and $33 \%$ having more than 1000 employees. Supervisory levels ranged from 20.3\% entry and low-level management, $30.4 \%$ mid-level management, $44.0 \%$ director or senior level executive, and $5.1 \%$ other. Participants had three to 57 years of workplace experience $(M=26.7 ; S D=11)$. Sixteen males and 62 females, with one respondent choosing not to indicate, participated in the study. Of the respondents, $48.1 \%$ indicated that they were involved in drafting the organization's anti-harassment policy and $75.9 \%$ were involved with enforcement.

Using a Likert scale (1=strongly agree, 2= agree, 3=somewhat agree, 4=neither agree nor disagree, $5=$ somewhat disagree, $6=$ disagree, and $7=$ strongly disagree), respondents were asked a variety of qualitative and quantitative questions related to (a) perceptions regarding preventing misconduct, (b) complaints mechanisms, and (c) allocation of sufficient time and resources toward the topic. Table 1 below indicates mean scores for these questions. An analysis comparing demographics and perceptions regarding current sexual harassment initiatives did not reveal a significant variance between industry type, organizational longevity, size, profit/non-profit status, as well as participant position level, longevity, and sex. Respondents were also provided qualitative questions allowing for clarification or elucidation. Findings reveal that respondents felt stronger that their organizations were committed to creating a culture that minimized sexual harassment $(M=1.86)$ than organizational leaders were providing resources $(M=2.65)$, time $(M=2.73)$, and communication $(M=2.60)$ aimed at preventing harassment.

Table 1: Perceptions regarding current sexual harassment initiatives

\begin{tabular}{l|r|r}
\hline & \multicolumn{1}{|c}{$\begin{array}{c}\text { Std. } \\
\text { Deviation }\end{array}$} \\
\hline My organization is active in preventing sexual harassment in the workplace. & 2.22 & 1.276 \\
\hline $\begin{array}{l}\text { My organization is committed to creating to a culture which minimizes sexual } \\
\text { harassment. }\end{array}$ & 1.86 & 1.144 \\
\hline $\begin{array}{l}\text { My company's leadership allocates sufficient staff time for the harassment } \\
\text { prevention efforts. }\end{array}$ & 2.73 & 1.519 \\
\hline $\begin{array}{l}\text { My company's leadership allocates sufficient resources for harassment prevention } \\
\text { Top executives clearly communicate to employees a commitment to foster a } \\
\text { harassment-free workplace. }\end{array}$ & 2.65 & 1.547 \\
\hline
\end{tabular}


Respondents were asked how their sexual harassment policy and training practices aligned with the EEOC's recommendation of respectful workplaces. Table 2 reveals the percentages of businesses who had implemented EEOC recommendations within their training or policy to deter misconduct. Findings revealed that less than $20 \%$ of respondents indicated that they provided examples of prohibited conduct, identified types of disciplinary actions, indicated the impartiality of their investigation, protected complainants from supervisor retaliation, protected witnesses from retaliation from supervisors or coworkers, and confirmed discipline for anyone who retaliates during a sexual harassment investigation. During debriefing sessions with HR practitioners, members confirmed findings that organizations had partially adhered to EEOC recommendations regarding training initiatives and were primarily relying on established policies and employee training to reduce misconduct and create or improve anti-harassment cultures within the workplace. Many within the debriefing sessions acknowledge that training and policy updates were needed within their organizations.

Table 2: Organizational Policy Regarding Conduct

\begin{tabular}{l|c}
\hline Policy \& Training Characteristics & $\begin{array}{c}\text { Percent Reporting } \\
\text { Policy Element }\end{array}$ \\
\hline $\begin{array}{l}\text { Includes an unequivocal statement that harassment based on ANY protected } \\
\text { characteristic is not tolerated }\end{array}$ & $24.89 \%$ \\
\hline Describes prohibited conduct & $21.89 \%$ \\
\hline Provides examples of prohibited conduct & $15.45 \%$ \\
\hline Explains the process of reporting prohibited conduct & $21.46 \%$ \\
\hline Identifies types of disciplinary actions available in sexual harassment disputes & $15.45 \%$ \\
\hline States that the reporting system provides an impartial investigation & $19.25 \%$ \\
\hline States that the reporting system provides a prompt investigation & $25.13 \%$ \\
\hline States that the reporting system provides a thorough investigation & $27.27 \%$ \\
\hline $\begin{array}{l}\text { States that the employer will take prompt corrective action upon a finding of } \\
\text { harassment }\end{array}$ & $24.06 \%$ \\
\hline States the identity of the complainant will be kept confidential, if possible & $35.04 \%$ \\
\hline States the identity of the witnesses will be kept confidential, if possible & $27.01 \%$ \\
\hline States the identity of the target will be kept confidential, if possible & $27.74 \%$ \\
\hline Confirms complainant's protection from retaliation by co-workers. & $20.87 \%$ \\
\hline Confirms complainant's protection from retaliation by supervisors. & $19.90 \%$ \\
\hline Confirms the organization protects witnesses from retaliation by co-workers. & $17.48 \%$ \\
\hline Confirms the organization protects witnesses from retaliation by supervisors. & $17.48 \%$ \\
\hline Confirms the organization will discipline any employee who retaliates against & $19.90 \%$ \\
\hline someone involved in a harassment investigation. & \\
\hline
\end{tabular}

Respondents were also asked how recent media coverage of \#MeToo and sexual harassment scandals appeared to impact organizational practices. Table 3 includes summary data from these questions. Findings reveal that respondents felt that recent media coverage and the \#MeToo movement had impacted harassment conversations within organization more than it had impacted victims making claims or conversations among senior leaders. Qualitative follow-up questions within the survey and feedback given within debriefing sessions indicated that employers felt that they were meeting a legal 
and compliance standard but did not comprehensively address all training and policy recommendations given by the EEOC. Additionally, respondents indicated a concern regarding minimizing misconduct, but in light of the \#MeToo movement, organizations had not recently nor were planning to implement additional initiatives to create anti-harassment cultures. One respondent wrote

It's a good idea to be able to feel comfortable enough to report sexual harassment. I definitely see why most women do not. The fear of not being believed or anything done about it. Blaming the victim, being questioned if you could have misunderstood what was being said or actions toward you.

In addition, during a survey debriefing session, an HR practitioner commented

We have good training in place and we have recently moved up our training frequency. I am in the risk business - minimizing risks for my company. I hope that improved training and frequency of training will be enough to reduce this risk. We tend not to have issues with sexual misconduct, but to be frank, I am not sure if training and policy enforcement is enough to insulate us from this problem.

Table 3: Media Coverage impact

\begin{tabular}{l|r|r}
\hline & & $\begin{array}{c}\text { Std. } \\
\text { Deviation }\end{array}$ \\
\hline \#MeToo has impacted sexual harassment claims in our organization. & 5.97 & 1.745 \\
\hline \#MeToo has impacted sexual harassment training in our organization. & 5.08 & 2.093 \\
\hline \#MeToo has impacted sexual harassment policy in our organization. & 5.68 & 1.866 \\
\hline \#MeToo has impacted HR conversations in our organization. & 4.77 & 2.210 \\
\hline \#MeToo has impacted conversations among senior organizational leaders. & 5.50 & 2.400 \\
\hline
\end{tabular}

\section{Discussion}

HR practitioners who participated in this study did not feel that \#MeToo had impacted their organization's sexual harassment prevention initiatives and reported that \#MeToo had not impacted overall claims within their workplaces. Respondents agreed that their organizations were active in preventing sexual harassment in the workplace; however, only $21.89 \%$ of respondents felt their training and policies described conduct that was prohibited, $21.46 \%$ explained the process of reporting prohibited conduct, $27.27 \%$ stated that their reporting system would provide a thorough investigation, and $24.06 \%$ stated that the organization would take prompt corrective action upon a finding of harassment. Only $15.45 \%$ of respondents indicated that their organizations provided examples of prohibit conduct and identified types of disciplinary actions available in sexual harassment investigations. Additionally, $17.48 \%$ of respondents confirmed their organization's protection of witnesses from co-worker or supervisor retaliation, and $19.9 \%$ confirmed complainant's protection from supervisor retaliation. Findings revealed that organizations must continue to improve workshop policies and training strategies to meet the EEOC recommended practices. Respondents also noted that the allocation of time, resources, and communication from senior leadership regarding harassment prevention could be improved. While not an egregious oversite, respondents indicated that allocation of time, resources and communication from leadership were not strongly observed.

Additionally, an unexpected and unintentional insight revealed within respondents' surveys and debriefing sessions was how narrowly focused business approaches were when creating anti-harassment cultures. Initial data collection, follow-up debriefing sessions, and data analysis revealed businesses were only partially implementing EEOC recommendations and most had focused their prevention initiatives 
primarily on employee training and/or organizational policies. When asked what initiatives were put in place to minimize sexual misconduct within their workplaces, respondents noted only training and policy programs were being used to drive anti-harassment cultures and other systematic initiatives, such as behavioral modeling was not proactively being used to establish and sustain anti-harassment cultures. Businesses within this research primarily implemented training and policy initiatives to meet EEOC's respectful workplace recommendations, and despite regulatory recommendations, most organizations did not fully meet the EEOC's suggested guidelines.

The creation of policy and development of training are not new initiatives in the quest to reduced workplace misconduct. As mentioned previously, cases such as Burlington Industries v. Ellerth (1998) and Farager v. Boca Raton (1998) have prompted the widespread adoption of specific sexual harassment policies to correct and prevent harassment occurrences within the workplace. Attempting to meet a recommended legal standard and reduce organizational liability, the majority of businesses have instituted yearly harassment prevention training program and maintain a documented harassment prevention policy. Fifty-seven percent of respondents within this study confirmed that their employees had participated in harassment prevention training during the last 12 months; additionally, 97\% of respondents indicated that their organization had a written anti-harassment policy and $95 \%$ felt their policy was easily understood. However, despite policy creation and training procedures, sexual harassment charges within U.S. organizations have remained constant (EEOC, 2018) and underreporting of sexual misconduct continues in current U.S. business environments (SHRM, 2018). A closer look at organizational policy and training characteristics revealed that organizations lack critical dynamics including specific examples of what is prohibited conduct, disciplinary actions for sexual misconduct, commitment to a prompt investigation, and protection from retaliation.

Only $15 \%$ of respondents indicated that news and media coverage of sexual misconduct had impacted their sexual harassment policies; respondents clarified that \#MeToo and the EEOC's respectful workplace initiatives had either not resulted in any meaningful changes within their organizations, or had prompted narrow efforts to ensure policy language and training guidance was up-to-date. When asked what new initiatives or innovative approaches were used to create anti-harassment cultures, respondents indicated only revised training schedules and curriculum changes. Absent from organizational initiatives to reduce misconduct were efforts outside of training and policy creation.

Based on national trends and data collected from this research, businesses must expand strategies to reduce harassment beyond policy creation and professional training. The establishment of policy and training is unlikely to sufficiently change behaviors and reduce the likelihood of sexual misconduct in the workplace (Roehling \& Huang, 2018). Taskforces, training, and policy creations are not enough to drive the adoption of anti-harassment cultures, as organizational change is not driven by regulatory scrutiny or policy implementation (Dobbin et al., 2011).

This analysis suggests that the creation of anti-harassment cultures should not be singularly viewed through a compliance framework (attend regular training and acknowledge employee standards), but rather layer current training and policy initiatives with a change management meta-framework of leadership modeling. Leadership modeling will allow employees to view the topic not from a lawsuit avoidance strategy, but from the context of preventing harassment because organizational human capital is valued. If training and policies continue to be updated, presented, and supported using several communication channels, HR practitioners execute impartial investigations and respond appropriately to workplace harassment, and leadership commit to modeling anti-harassment behaviors, cultural shifts are more likely to occur. Thus, enhancing training and policy practices with leadership modeling allows the organization's focus to become behaviorally driven rather than compliance driven. 


\section{Practical Implications}

This research has several practical implications for leadership and management educators and practitioners. Findings demonstrate that policy creation and training improvements, albeit necessary and relevant, are likely to inadequately address current workplace issues related to sexual harassment. Establishing a comprehensive policy and providing thorough and engaging training are essential elements; however, these strategies should not be viewed as exhaustive approaches to improve organizational cultures. Modeling by organizational leaders can play a critical role in addressing the affective, cognitive, and behavioral resistance felt when attempting to change business culture.

Behavioral modeling can also allow leaders to leverage their power and influence to positively develop their human capital (Bottomley et al., 2014) and can be accomplished through strategic initiatives. Articulating through multiple communication channels a clear vision of how the organization will not tolerate any form of harassments is a key first step. Establishing an overt link between valuing the organization's human capital with other recognized critical success factors, such as a commitment to continuous improvement, customer service, cost efficiency, quality products/services, or teamwork will allow leaders to connect a new and needed plan to an established and accepted belief system. Asking questions of diverse employees throughout the organization regarding how the company can minimize misconduct and promote anti-harassment cultures will enlist employee buy-in and propel cultural awareness. Leaders can also act in ways that drive and confirm the value of a safe and productive workplace. Their goal should be to brand the company as an organization which values its diverse employees. Commitment to frequent, open, and honest communication regarding harassment prevention as well as identifying, acknowledging, and removing barriers which have prevented antiharassment cultures are fundamental to behavioral modeling. Finally, appreciating and rewarding positive collaboration and workplace civility provides an additional opportunity for employees to see leadership's commitment to creating anti-harassment cultures.

Creating opportunities for leaders to advocate and advance a more harassment-free culture demonstrates that this initiative is more than a mere compliance or risk issue. Behavioral and attitudinal changes cannot occur without organizational leaders' and managers' support and sustainment (Ashnai et al., 2016; Brown \& Treviño, 2006; Freiwald et al., 2015). Modeling of anti-harassment behaviors will influence employee's future decision making, promote workplace civility behaviors, and minimize counterproductive behaviors which perpetuate harassment cultures.

\section{Limitation, Future Direction, and Conclusion}

This research, while innovative and timely, has several limitations. Research intent was not to criticize organizational policies and training regarding the creation of anti-harassment cultures, but rather to propose an additional framework for creating change within organizations. This research study was conducted within eight months of the onset of \#MeToo movement and the EEOC's revised recommendations for businesses, which may not have allowed businesses sufficient time to develop and implement new workplace strategies. Respondents were HR practitioners, many of whom were instrumental in creating their organization's policies and training programs; their perceptions of whether their organizations needed a shift in culture may have been biased or self-serving. This study provided respondents the opportunity to clarify their organizations' initiatives regarding creating anti-harassment cultures; while specific questions were asked about the EEOC's recommendations, the study could have 
benefited from elucidating questions aimed at change management dynamics, including more specific behavioral modeling strategies used by organizational leaders.

This analysis provides an interesting avenue for future examination of strategies used by businesses to create and sustain anti-harassment cultures and further leadership research regarding the direct and indirect benefits, techniques, and approaches used to leverage behavioral modeling and cultural change. Follow-up research should continue to investigate organizational adoption of EEOC recommendations and how managers have created safe and productive work environments and leaders have created anti-harassment cultures. Additionally, layering other workplace trends such as remote work and women in leadership with current anti-harassment initiatives would provide an interesting avenue of future research.

Future research should also address strategies for using positive role modeling to change attitudes and behaviors as well as the negative outcomes of undesirable role modeling on cultural change. Examining how behavioral modeling may be effectively operationalized by organizational leaders is also an area of valuable future scholarship. Research recommendations include moving beyond specific modeling measures to examine the relationship between leadership innovations and shifting organizational cultures. Finally, as many organizational leaders and HR practitioners consider \#MeToo and sexual misconduct as a significant fiduciary threat and organizational risk, (Crabb, 2018; Hemel \& Lund, 2018), additional research is essential to determining how organizations can successfully induce antiharassment cultures.

Organizational changes are necessary to survive and thrive in today's competitive market. To facilitate organizational change towards attaining anti-harassment cultures, organizational leaders should focus initiatives not only regarding accountability but also toward the creation of equality climates. The signal for change must be given by leaders. Activating behavioral role models is essential to institutionalizing anti-harassment cultures within organizations. 


\section{References}

Ajzen, I., \& Fishbein, M. (1977). Attitude-behavior relations: A theoretical analysis and review of empirical research. Psychological Bulletin, 84(5), 888-918. doi:10.1037/0033-2909.84.5.888

Annosi, M. C., Martini, A., Brunetta, F., \& Marchegiani, L. (2018). Learning in an agile setting: A multilevel research study on the evolution of organizational routines. Journal of Business Research, (in press). doi:10.1016/j.jbusres.2018.05.011

Ashnai, B., Henneberg, S. C., Naudé, P., \& Francescucci, A. (2016). Inter-personal and inter-organizational trust in business relationships: An attitude-behavior-outcome model. Industrial Marketing Management, 52, 128-139. doi:10.1016/j.indmarman.2015.05.020

Back, C. J. \& Freeman, W. C. (2018, April 9). Sexual Harassment and Title VII: Selected legal Issues. Congressional Research Service, 7-5700, R45155. Retrieved from https://fas.org/sgp/crs/misc/R45155.pdf

Bandura, A. (1989). Human agency in social cognitive theory. American Psychologist, 44(9), 1175-1184. doi:10.1037/0003-066X.44.9.1175

Barnes v. Costle, 561 F.2d 983 (D.C. Cir. 1977).

Battilana, J. \& Casciaro, T. (2013). Overcoming resistance to organizational change: Strong ties and affective cooptation. (2013). Management Science, 59(4), 819-836. doi:10.1287/mnsc.1120.1583

Becton, J. B., Gilstrap, J. B., \& Forsyth, M. (2017). Preventing and correcting workplace harassment: Guidelines for employers. Business Horizons, 60(1), 101-111. https://doi.org/10.1016/j.bushor.2016.09.005

Benavides-Espinoza, C., \& Cunningham, G. B. (2010). Bystanders' reactions to sexual harassment. Sex Roles, 63(3/4), 201-213. doi:10.1007/s11199-010-9781-7

Berson, Y., Da'as, R., \& Waldman, D. A. (2015). How do leaders and their teams bring about organizational learning and outcomes? Personnel Psychology, 68(1), 79-108. doi:10.1111/peps.12071

Boje, D. M., Rosile, G. A., Durant, R. A., \& Luhman, J. T. (2004). Enron spectacles: A critical dramaturgical analysis. Organization Studies, 25(5), 751-774. doi:10.1177/0170840604042413

Bottomley, K., Burgess, S., \& Fox, M. (2014). Are the behaviors of transformational leaders impacting organizations? A study of transformational leadership. International Management Review, 10(1). 5-9.

Brown, M. E. \& Treviño, L. K. (2006). Ethical leadership: A review and future directions. The Leadership Quarterly, 17(6), 595-616. doi:10.1016/j.leaqua.2006.10.004

Brown, M. E., Treviño, L. K., Harrison, D. A. (2006). Ethical leadership: A social learning perspective for construct development and testing. Organizational Behavior and Human Decision Process, 97(2), 117-134. doi:10.1016/j.obhdp.2005.03.002

Burlington Industries, Inc. v. Ellerth, 524 U.S. 742 (1998).

Burnaska, R. F. (1976). The effects of behavior modeling training upon managers' behaviors and employees' perceptions. Personnel Psychology, 29(3), 329-335. https://doi.org/10.1111/j.17446570.1976.tb00416.x

Chatterjee, A. \& Hambrick, D. (2007). It's all about me: Narcissistic chief executive officers and their effects on company strategy and performance. Administrative Science Quarterly, 52(3), 351-386. 
Cheung, H., Goldberg, C. B., King, E. B., \& Magley, V. J. (2018). Are they true to the cause? Beliefs about organizational and unit commitment to sexual harassment awareness training. Group \& Organization Management, 43(4), 53-560. doi:10.1177/1059601117726677

Chung, S., Su, Y., \& Su, Y. (2012). The impact of cognitive flexibility on resistance to organizational change. Social Behavior \& Personality: An International Journal, 40(5), 735-745. doi:10.2224/sbp.2012.40.735

Cinite, I., \& Duxbury, L. E. (2018). Measuring the behavioral properties of commitment and resistance to organizational change. The Journal of Applied Behavioral Science, 54(2), 113-139. doi:10.1177/0021886318757997

Crabb, J. (2018). Rise of 'Weinstein clauses' to shield parties during deal-making. International Financial Law Review.

De Luca, P. \& Rubio, M. C. (2019). The curve of knowledge transfer: A theoretical model. Business Process Management Journal, 25(1), 10-26, doi:10.1108/BPMJ-06-2017-0161

Denison, D., \& Mishra, A. (1995). Toward a theory of organizational culture and effectiveness. Organization Science, 6(2), 204-223.

Dragoni, L. (2005). Understanding the emergence of state goal orientation in organizational work groups: The role of leadership and multilevel climate perceptions. Journal of Applied Psychology, 90, 1084 -1095. doi:10.1037/0021-9010.90.6.1084

Dobbin, F., Kim, S., \& Kalev, A. (2011). You can't always get what you need: Organizational determinants of diversity programs. American Sociological Review, 76(3), 386-411. doi:10.1177/0003122411409704

Dotlich, D. L., \& Cairo, P. C. (2003). Why CEOs fail. San Francisco, CA: Jossey-Bass

EEOC. (2018). Equal Employment Opportunity Commission. Sexual harassment. Retrieved from https://www.eeoc.gov/laws/types/sexual_harassment.cfm

Ellinas, C., Allan, N., \& Johansson, A. (2017). Dynamics of organizational culture: Individual beliefs vs. social conformity. PLoS ONE, 12(6), 1-20. https://doi.org/10.1371/journal.pone.0180193

Faragher v. City of Boca Raton, WS 336322 U. S. (1998)

Folz, C. (2016, June 19). No evidence that training prevents harassment, finds EEOC task force. Retrieved from https://shrm.org/hr-today/news/hr-news/Pages/EEOC-Harassment-Task-Force.aspx

Fortado, S. (2018). Workplace sexual abuse, labor and the \#MeToo movement. Labor Studies Journal, 43(4), 241-244. doi:10.1177/0160449X18809431

Freiwald, D. R., O'Toole, M. F., Smith, M. O., \& Thropp, J. E. (2015). Modeling the dimensions of ethical leadership \& safety climate in aviation \& healthcare. Journal of Safety, Health \& Environmental Research, 11(2), 253-260.

García-Morales, V. J., Jiménez-Barrionuevo, M. M., \& Gutiérrez-Gutiérrez, L. (2012). Transformational leadership influence on organizational performance through organizational learning and innovation. Journal of Business Research, 65, 1040-1050. doi:10.1016/j.jbusres.2011.03.005

Gertner, N. (2018). Sexual Harassment and the bench. Judges' Journal, 57(4), 24-29.

Greene, B. (2018). Ensuring that \#MeToo is \#NotUs: Using HCM technology to combat sexual harassment. Workforce Solutions Review, July-September, 10-14. 
Haller, B. L. (2018). Sexual harassment in the workplace: Legal attempts to resolve a cultural problem. Faculty Works: Business. 45.

Harris v. Forklift Systems, Inc. (1993). 92-1168.

Hemel, D., \& Dorothy, L. S. (2018). Sexual harassment and corporate law. Columbia Law Review, 118(6), 1583-1680.

Hennekam, S., \& Bennett, D. (2017). Sexual harassment in the creative industries: Tolerance, culture and the need for change. Gender, Work \& Organization, 24(4), 417-434. doi:10.1111/gwao.12176

Herscovitch, L., \& Meyer, J. P. (2002). Commitment to organizational change: Extension of a threecomponent model. Journal of Applied Psychology, 87(3), 474-487. doi:10.1037/00219010.87.3.474

Hinyard, L. J., \& Kreuter, M. W. (2007). Using narrative communication as a tool for health behavior change: A conceptual, theoretical, and empirical overview. Health Education \& Behavior, 34(5), 777-792. doi:10.1177/1090198106291963

Ho, M. (2016, November 1). Investment in learning increases for fourth straight year. Association for Talent Development. Retrieved from https://www.td.org/magazines/td-magazine/investment-inlearning-increases-for-fourth-straight-year

Holland, R. W., Verplanken, B., \& van Knippenberg, A. (2002). On the nature of attitude-behavior relations: the strong guide, the weak follow. European Journal of Social Psychology, 32(6), 869876. doi:10.1002/ejsp.135

Jackson, L. (2018, Summer). Class action trends report, Spring 2018. Labor Law Journal, 85-99.

Jackson, R. A. (2018, May 31). Into the light. Retrieved from Internal Auditor: https://www.iia.nl/SiteFiles/IA/ia201806-IntoTheLight.pdf

Jacobs, C., \& Coghlan, D. (2005). Sound from silence: On listening in organizational learning. Human Relations, 58(1), 115-138. doi:10.1177/0018726705050938

Johnson, S. L. (2018). The \#MeToo movement: Up close and personal. HR Professional, 35(8), 11.

Kellogg, K. C. (2011). Hot lights and cold steel: Cultural and political toolkits for practice change in surgery. Organization Science, 22(2), 482-502. doi:10.1287/orsc.1100.0539.

Knottnerus, D. J., Ulsperger, J. S., Cummins, S., \& Osteen, E. (2006). Exposing Enron: Media representations of ritualized deviance in corporate culture. Crime, Media, Culture, 2(2), 177-195. doi:10.1177/1741659006065405

Kroesen, M., Handy, S., \& Chorus, C. (2017). Do attitudes cause behavior or vice versa? An alternative conceptualization of the attitude-behavior relationship in travel behavior modeling. Transportation Research Part A, 101, 190-202. doi:10.1016/j.tra.2017.05.013

Lacerenza, C. N., Reyes, D. L., Marlow, S. L., Joseph, D. L., \& Salas, E. (2017). Leadership training design, delivery, and implementation: A meta-analysis. Journal of Applied Psychology, 102(12), 16861718. https://doi.org/10.1037/apl0000241

Litzky, B. E., Eddleston, K. A., \& Kidder, D. L. (2006). The good, the bad, and the misguided: How managers inadvertently encourage deviant behaviors. Academy of Management Perspectives, 20(1), 91103. doi:10.5465/AMP.2006.19873411

BRUE / DOI: 10.5929/2021.11.1.2 
Manz, C. C., \& Sims Jr., H. P. (1981). Vicarious learning: The influence of modeling on organizational behavior. Academy of Management Review, 6(1), 105-113. https://doi.org/10.5465/AMR.1981.4288021

Meritor Savings Bank v. Vinson, 477 U.S. 57 (1986).

Moore, C., Mayer, D. M., Chiang, F. F. T., Crossley, C., Karlesky, M. J., \& Birtch, T. A. (2019). Leaders matter morally: The role of ethical leadership in shaping employee moral cognition and misconduct. Journal of Applied Psychology, 104(1), 123-145. doi:10.1037/apl0000341

Moses, J. L., \& Ritchie, R. J. (1976). Supervisory relationships training: A behavioral evaluation of a behavior modeling program. Personnel Psychology, 29(3), 337-343. https://doi.org/10.1111/j.17446570.1976.tb00417.x

O'Donohue, W., Downs, K., \& Yeater, E. A. (1998, Summer). Sexual harassment: A review of the literature. Aggression and Violent Behavior, 3(2), 111-128. https://doi.org/10.1016/S1359-1789(97)00011-6

Owens, B. P., \& Hekman, D. R. (2012). Modeling how to grow: An inductive examination of humble leader behaviors, contingencies, and outcomes. Academy of Management Journal, 55(4), 787-818. doi:10.5465/amj.2010.0441

Piderit, S. K. (2000). Rethinking resistance and recognizing ambivalence: A multidimensional view of attitudes toward an organizational change. Academy of Management Review, 25(4), 783-794. doi:10.5465/AMR.2000.3707722

Prasad, V. (2018). If anyone is listening, \#MeToo: Breaking the culture of silence around sexual abuse through regulating non-disclosure agreements and secret settlements. Boston College Law School, 59(7), 2507-2549.

Quick, J. C., \& McFadyen, M. A. (2017). Sexual harassment: Have we made any progress? Journal of Occupational Health Psychology, 22(3), 286-298. doi:10.1037/ocp0000054

Roehling, M. V., \& Huang, J. (2018). Sexual harassment training effectiveness: An interdisciplinary review and call for research. Journal of Organizational Behavior, 39(2), 134-150. doi:10.1002/job.2257

Sarros, J. C., Cooper, B. K., \& Santora, J. C. (2008). Building a climate for innovation through transformational leadership and organizational culture. Journal of Leadership \& Organizational Studies, 15(2), 145-158. doi:10.1177/1548051808324100

Schein, E. H. (2004). Organizational culture and leadership. San Francisco, CA: Jossey-Bass.

Sherwyn, D., Heise, M., \& Eigen, Z. J. (2001). Don't train your employees and cancel your "1-800" harassment hotline: an empirical examination and correction of the flaws in the affirmative defense to sexual harassment charges /. Fordham Law Review, 69(4), 1265-1304

Shugerman, E. (2017) Me Too: Why are women sharing stories of sexual assault and how did it start? Independent, 17. Retrieved from http://www.independent.co.uk/news/world/ americas/me-toofacebook-hashtag-why-when meaning-sexualharassment-rape-stories-explained-a8005936.html

SHRM. (2018). SHRM research finds some employees unaware of company sexual harassment policies. Retrieved from https://www.shrm.org/about-shrm/press-room/press-releases/pages/sexualharassment-survey.aspx

Siegel, J. T., Navarro, M. A., Tan, C. N., \& Hyde, M. K. (2014). Attitude-behavior consistency, the principle of compatibility, and organ donation: A classic innovation. Health Psychology, 33(9), 1084-1091. doi:10.1037/hea0000062 
Sims, R. R. \& Brinkmann, J. (2002). Leaders as moral role models: The case of John Gutfreund at Salomon Brothers. Journal of Business Ethics, 35(4), 327-39. doi:10.1023/A:1013826126058

Soni, R. G., \& Soni, B. (2018). Manufacturing Operations: Sexual Harassment, Morality, and Frontline Employees. Competition Forum, 16(2), 30-38.

Soucek, B., \& Schultz, V. (2019). Sexual harassment by any other name. University of Chicago Legal Forum, 2019(8). 227-259. Retrieved from https://chicagounbound.uchicago.edu/uclf/vol2019/iss1/8?utm source=chicagounbound.uchic ago.edu\%2Fuclf\%2Fvol2019\%2Fiss1\%2F8\&utm medium=PDF\&utm campaign=PDFCoverPages

Stan, M. \& Puranam, P. (2017). Organizational adaptation to interdependence shifts: The role of integrator structures. Strategic Management Journal, 38, 1041-1061. doi:10.1002/smj.2546

Traub, A. J., \& Van Hoose Garofalo, A. (2019). \#MeToo - A brief review. Employee Relations Law Journal, 44(4), 4-7.

Treviño, L. K. \& Brown, M. E. (2005), The role of leaders in influencing unethical behavior in the workplace, in Kidwell, R. E. and Martin, C. L. (Eds), Managing Organizational Deviance, (pp.69-96). London, England: Sage Publishing.

Tonowski, R. (2018). On the Legal Front: You Say You Want a Revolution. TIP: The Industrial-Organizational Psychologist, 55(4), 1-6.

Waldman, D., Ramírez, G., House, R., \& Puranam, P. (2001). Does leadership matter? CEO leadership attributes and profitability under conditions of perceived environmental uncertainty. The Academy of Management Journal, 44(1), 134-143. Retrieved from http://www.jstor.org.ezproxy.cameron.edu/stable/3069341

Xie, L. (2019). Leadership and organizational learning culture: A systematic literature review. European Journal of Training and Development, 43(1/2), 76-104. doi:10.1108/EJTD-06-2018-0056

Xiong, Y., Cho, M., \& Boatwright, B. (2019). Hashtag activism and message frames among social movement organizations: Semantic network analysis and thematic analysis of Twitter during the \#MeToo movement. Public Relations Review, 45(1), 10-23. doi:10.1016/j.pubrev.2018.10.014

Yaffe, T., \& Kark, R. (2011). Leading by example: The case of leader OCB. Journal of Applied Psychology, 96(4), 806-826. doi:10.1037/a0022464

Zhang, Y., Zhang, L., Liu, G., Duan, J., Xu, S., \& Cheung, M. W.-L. (2019). How does ethical leadership impact employee organizational citizenship behavior? A meta-analytic review based on two-stage metaanalytic structural equation modeling (TSSEM). Zeitschrift Für Psychologie, 227(1), 18-30. https://doi.org/10.1027/2151-2604/a000353

Zimmerman, J. (2006). Why some teachers resist change and what principals can do about it. NASSP Bulletin, 90(3), 238-249. 


\section{About the Author}

Dr. Krystal Brue (kbrue@cameron.edu) is an Associate Professor of Management and Chair of the Department of Business in the School of Graduate and Professional Studies at Cameron University in Lawton, OK. She has over 25 years of human resource, organizational behavior, and training and development experience. 